\title{
Mechanisms of lead, copper, and zinc retention by phosphate rock
}

\author{
Xinde Cao , Lena Q. Ma, Dean R. Rhue, Chip S. Appel
}

\begin{abstract}
"Capsule": Phosphate-induced formation of fluoropyromorphite is primarily responsible for $\mathrm{Pb}$ immobilization by phosphate rock, whereas $\mathrm{Cu}$ and $\mathrm{Zn}$ retention is mainly attributable to the surface adsorption or complexation.
\end{abstract}

\begin{abstract}
The solid-liquid interface reaction between phosphate rock $(\mathrm{PR})$ and metals $(\mathrm{Pb}, \mathrm{Cu}$, and $\mathrm{Zn})$ was studied. Phosphate rock has the highest affinity for $\mathrm{Pb}$, followed by $\mathrm{Cu}$ and $\mathrm{Zn}$, with sorption capacities of 138,114 , and $83.2 \mathrm{mmol} / \mathrm{kg} \mathrm{PR}$, respectively. In the $\mathrm{Pb}-\mathrm{Cu}-\mathrm{Zn}$ ternary system, competitive metal sorption occurred with sorption capacity reduction of $15.2 \%, 48.3 \%$, and $75.6 \%$ for $\mathrm{Pb}, \mathrm{Cu}$, and $\mathrm{Zn}$, respectively compared to the mono-metal systems. A fractional factorial design showed the interfering effect in the order of $\mathrm{Pb}>\mathrm{Cu}>\mathrm{Zn}$. Desorption of $\mathrm{Cu}$ and $\mathrm{Zn}$ was sensitive to $\mathrm{pH}$ change, increasing with $\mathrm{pH}$ decline, whereas $\mathrm{Pb}$ desorption was decreased with a strongly acidic TCLP extracting solution $(\mathrm{pH}=2.93)$. The greatest stability of $\mathrm{Pb}$ retention by $\mathrm{PR}$ can be attributed to the formation of insoluble fluoropyromorphite $\left[\mathrm{Pb}_{10}\left(\mathrm{PO}_{4}\right)_{6} \mathrm{~F}_{2}\right]$, which was primarily responsible for $\mathrm{Pb}$ immobilization (up to $78.3 \%$ ), with less contribution from the surface adsorption or complexation $(21.7 \%$ ), compared to $74.5 \%$ for $\mathrm{Cu}$ and $95.7 \%$ for $\mathrm{Zn}$. Solution $\mathrm{pH}$ reduction during metal retention and flow calorimetry analysis both supported the hypothesis of retention of $\mathrm{Pb}, \mathrm{Cu}$, and $\mathrm{Zn}$ by surface adsorption or complexation. Flow calorimetry indicated that $\mathrm{Pb}$ and $\mathrm{Cu}$ adsorption onto $\mathrm{PR}$ was exothermic, while $\mathrm{Zn}$ sorption was endothermic. Our research demonstrated that PR can effectively remove Pb from solutions, even in the presence of other heavy metals (e.g. $\mathrm{Cu}, \mathrm{Zn}$ ).
\end{abstract}

\section{Introduction}

Significant effort has been made to evaluate the effectiveness of phosphate on in situ remediation of contaminated waters and soils (Basta et al., 2001; Cotter-Howells and Caporn, 1996; Hettiarachchi et al., 2000; Ma et al., 1995; Yang et al., 2001). Phosphate minerals, i.e. phosphate rock (PR) and hydroxyapatite, have been shown to effectively immobilize $\mathrm{Pb}$ from various contaminated waters and soils (Cao et al., 2002; Ma et al., 1995; Ryan et al., 2001). Takeuchi and Arai (1990) suggested that $\mathrm{Pb}$ immobilization resulted from the formation of a more stable lead phosphate, such as $\mathrm{Ca}_{(10-x)}$ $\mathrm{Pb}_{x}\left(\mathrm{PO}_{4}\right)_{6}(\mathrm{OH})_{2}$ via an ion exchange mechanism where aqueous $\mathrm{Pb}$ replaces $\mathrm{Ca}$ on the hydroxyapatite lattice. Ma et al. (1995), on the other hand, proposed dissolution of phosphate rock and subsequent precipitation of a pyromorphite-like mineral $\left(\mathrm{Pb}_{10}\left(\mathrm{PO}_{4}\right)_{6} X_{2}, X=\mathrm{OH}\right.$, $\mathrm{Cl}, \mathrm{F})$ as the primary mechanism. In addition to $\mathrm{Pb}$, phosphate rock can also remove $\mathrm{Zn}$ and $\mathrm{Cd}$ from aqueous solutions. The possible mechanisms for metal retention 
by phosphate minerals included: (1) ion exchange processes at the surface of PR (Middelburg and Comans, 1991; Xu et al., 1994); (2) surface complexation (Xu et al., 1994); (3) precipitation of some amorphous to poorly crystalline, mixed metal phosphates (Ma et al., 1995); and (4) substitution of $\mathrm{Ca}$ in PR by other metals during recrystallization (coprecipitation) (Chen et al., 1997; Jeanjean et al., 1994; Xu et al., 1994). However, it is difficult to quantify the relative contribution from each mechanism that is responsible for metal removal and it appears that all four mechanisms may work together. As such, estimating the extent of each mechanism contributing to metal retention by PR has not been reported. In addition, contaminated soils commonly encountered multi-metals including $\mathrm{Pb}, \mathrm{Cu}, \mathrm{Zn}, \mathrm{Cr}, \mathrm{Cd}$ and $\mathrm{Ni}$ (Ma et al., 1995). Competitive retention of these metals onto phosphate minerals has not been well studied, and individual metal immobilization mechanisms are still not fully understood.

Metal sorption is a competitive process between metals in solution and those sorbed onto the solid surface (Echeverria et al., 1998; Harter, 1992). Consequently, solution metal composition strongly affects metal retention onto solid surfaces. Many multi-metal sorption studies focused on the effects of $\mathrm{Ca}, \mathrm{Mg}$, and $\mathrm{K}$ on heavy metal retention by soil (Elrashidi and O'Connor, 1982). Harter (1992) evaluated the sorption of $\mathrm{Ni}, \mathrm{Co}$, and $\mathrm{Cu}$ in binary and ternary systems. Nickel did not affect copper sorption, but Co retention decreased in proportion to $\mathrm{Ni}$ sorption due to their chemical similarity. Many studies, looking at the sorption of heavy metals (i.e. $\mathrm{Pb}, \mathrm{Cu}, \mathrm{Zn}, \mathrm{Cd}$, and $\mathrm{Ni}$ ) using pure minerals (i.e. goethite, alumina, kaolinite, and zeolite), have demonstrated greater $\mathrm{Pb}$ selectivity relative to other heavy metals (Ahmed et al., 1998; Gomes et al., 2001).

Fractional factorial designs are a powerful tool commonly used to identify factors or variables that have an effect on a certain response (Echeverria et al., 1998). In a system characterized by several potentially influential factors, fractional factorial designs are most useful because it is possible to determine which variables are most important. Among those important variables, the magnitude and the direction of their influence can also be determined. Because of the complexity of the retention process, it is useful to combine sorption isotherms with fractional factorial designs to provide information about competition of heavy metals for solid-surface sites (Echeverria et al., 1998). Flow calorimetry, which directly and quantitatively measures the heat of a sorption reaction on an interface, is ideally suited for measuring interactions at the liquid-solid interface (Steinberg, 1981). This helps to better understand the binding strength of a particular reactive species onto the solid surface. Flow calorimetry has been used to study the surface chemistry of solids
(Appel et al., 2002; Rhue et al., 2002), but no study has been conducted on the surface reaction of metals with phosphate minerals.

The objective of this research was to characterize the mono-metal and multi-metal interactions of $\mathrm{Pb}, \mathrm{Cu}$, and $\mathrm{Zn}$ on the surface of PR. The specific aims were: (1) to compare metal sorption and desorption onto $\mathrm{PR}$ in mono-metal and multi-metal systems; (2) to examine the individual effect of a metal on the retention of other metals based on a fractional factorial design; (3) to determine the enthalpies of $\mathrm{Pb}, \mathrm{Cu}$, and $\mathrm{Zn}$ interfacial reactions onto PR using flow calorimetry; and (4) to quantify the contributions from different mechanisms responsible for metal retention by $\mathrm{PR}$.

\section{Materials and methods}

The mineral phosphate rock (PR) used in this study was from PCS Phosphate Mining Company (White Springs, Florida). The PR sample was classified as ground concentrated. Its preparation included airdrying, passing through a $0.425-\mathrm{mm}$ sieve, and rinsing with deionized water. Fluoroapatite $\left(\mathrm{Ca}_{10}\left(\mathrm{PO}_{4}\right)_{6} \mathrm{~F}_{2}\right)$ was identified as a major component of this PR, contributing its great potential to retain heavy metals in aqueous environments (Singh et al., 2001). The characteristics of the PR were presented in Singh et al. (2001). All reagents were of analytical grade, and deionized water was used throughout the experiment. Individual aqueous solutions of $\mathrm{Pb}, \mathrm{Cu}$, and $\mathrm{Zn}$ were prepared at concentrations of $15 \mathrm{mM}$ from their nitrate salts. Solution ionic strength was controlled at $0.05 \mathrm{M}$ using a $\mathrm{KNO}_{3}$ background electrolyte solution. The experiments were run in triplicate.

\subsection{Sorption of mono-metal and multi-metal}

Two sets of experiments were designed including $\mathrm{pH}-$ control sorption system and $\mathrm{pH}$-free control sorption system. For the $\mathrm{pH}$-control sorption, a series of $30 \mathrm{~mL}$ of $0.05 \mathrm{M} \mathrm{KNO}_{3}$ containing different concentrations $(0-0.6 \mathrm{mM})$ of either one or an equal-molar mixture of $\mathrm{Pb}, \mathrm{Cu}$, and $\mathrm{Zn}$ were added to $0.100 \mathrm{~g}$ of $\mathrm{PR}$. The suspensions were shaken at $30 \pm 1 \mathrm{rpm}$ on a reciprocating shaker for 24 -h at $25 \pm 2{ }^{\circ} \mathrm{C}$, which was required to reach equilibrium based on our preliminary kinetic experiments (data not shown). Solution $\mathrm{pH}$ was controlled at $5.5 \pm 0.2$ with diluted $\mathrm{HCl}$ and $\mathrm{NaOH}$. The supernatants were separated by centrifugation at $13,200 \times \mathrm{g}$ for $25 \mathrm{~min}$, and filtered through a $0.45-\mu \mathrm{m}$ polypropylene membrane filter. The filtrate was retained for analysis of $\mathrm{pH}, \mathrm{P}, \mathrm{Ca}$, $\mathrm{Pb}, \mathrm{Cu}$, and $\mathrm{Zn}$. Treatment blanks carrying $30 \mathrm{~mL}$ of $0.05 \mathrm{M} \mathrm{KNO}_{3}$ with $0.100 \mathrm{~g}$ of PR were included. The amount of adsorbed metal was taken as the difference between the amount added initially and that remaining in 
solutions after equilibration. In addition to the solution analysis, the solid residue of mono-metal reaction was collected at the end of reaction and dried at $35^{\circ} \mathrm{C}$. The dried solid residue was prepared on the tiles for X-ray powder diffraction analysis.

In comparison to the $\mathrm{pH}$-control system, a acidity free control system was set up to elucidate what happened to the proton during metal uptake. To $0.100 \mathrm{~g}$ of PR, a set of $30 \mathrm{~mL}$ of $0.05 \mathrm{M} \mathrm{KNO}_{3}$ containing different concentrations $(0-0.6 \mathrm{mM})$ of individual $\mathrm{Pb}, \mathrm{Cu}$, and $\mathrm{Zn}$ were added. The suspensions were shaken at $30 \pm 1 \mathrm{rpm}$ on a reciprocating shaker. After $24-\mathrm{h}$ equilibration, solution $\mathrm{pH}$ was recorded.

\subsection{Desorption of multi-metal}

To determine the stability of the heavy metal adsorbed by PR, desorption experiments were conducted. Four extracting solutions of varying $\mathrm{pH}$ were prepared to evaluate the stability of PR after interaction with aqueous metal solutions. Two of the extracting solutions were prepared from acetic acid at $\mathrm{pH} 2.93$ and 4.93 following the extraction fluids used in the EPA Toxicity Characteristic Leaching Procedure (USEPA, 1992). The other two extracting solutions used in this study were slightly acidic at $\mathrm{pH} 7$ and neutral at $\mathrm{pH} 9$ prepared by diluting concentrated $\mathrm{HNO}_{3}$ and $\mathrm{NaOH}$ solution.

After multi-metal sorption experiments as described in Section 2.1, the remaining solid residues from PR reaction with $0.4 \mathrm{mM}$ metals were chosen and washed twice with deionized water and supernatants were discarded immediately after 25-min of centrifugation. The washed residues were then treated with $30 \mathrm{~mL}$ of the extracting solutions of $\mathrm{pH} 3-9$ and the slurries were shaken on a reciprocating shaker for $24 \mathrm{~h}$. The slurries were centrifuged and their supernatants were filtered and analyzed for $\mathrm{pH}, \mathrm{Cu}, \mathrm{Pb}$, and $\mathrm{Zn}$.

\subsection{Competitive effects of multi-metal}

To ascertain the individual effects of a metal on the retention of other metals, a fractional factorial design, for three variables at two levels and four runs, was applied (Echeverria et al., 1998). The two levels included an initial metal concentration corresponding to the capacity, which is determined as the Point $B$ from a mono-metal sorption isotherm (Echeverria et al., 1998), and an initial concentration of zero. According to Gregg and Sing (1982), Point $B$ is the amount of metal retained at the plateau or at the beginning of the linear portion above the isotherm's knee, which is obtained from the intersection of tangents to the origin and plateau of isotherms. Each experiment was carried out by equilibrating $0.100 \mathrm{~g}$ of PR with $30 \mathrm{~mL}$ of $0.05 \mathrm{M}$ $\mathrm{KNO}_{3}$ solution containing the concentrations of metals corresponding to the experimental design (Table 3).
Solution $\mathrm{pH}$ was adjusted at $5.5 \pm 0.2$ with diluted $\mathrm{HCl}$ and $\mathrm{NaOH}$. The amount of each metal retained by the $\mathrm{PR}$ in each experiment was determined as previously described for sorption isotherms in Section 2.1. The interfering effect of one metal on the other metals was assessed on a relative basis by comparing the retained amount with Point $B$ of mono-metal isotherms.

\subsection{Calorimetric measurements}

Heats $(\Delta H)$ of $\mathrm{Pb}, \mathrm{Cu}$, and $\mathrm{Zn}$ sorption onto PR were determined using flow calorimetry (Appel et al., 2002; Rhue et al., 2002). Amounts of $120 \pm 0.5 \mathrm{mg}$ of PR $(0.25-0.50 \mathrm{~mm})$ were placed in the column of the flow calorimeter. The mobile phase of $30 \mathrm{mM} \mathrm{KNO}_{3}$ flowed through the column using a total pressure drop of about $100 \mathrm{~cm}$ of water. Flow rates were controlled with a precision needle valve at the outlet side of the calorimeter and were generally in the range of $0.27-$ $0.35 \mathrm{~mL} / \mathrm{min}$. After a satisfactory baseline was obtained with $30 \mathrm{mM} \mathrm{KNO}_{3}$ equilibration, solution of $15 \mathrm{mM}$ $\mathrm{Ca}\left(\mathrm{NO}_{3}\right)_{2}$ was then reacted with the $\mathrm{K}$-saturated $\mathrm{PR}$ and heats of exchange were determined. The $\mathrm{K}$ and $\mathrm{Ca}$ solutions were cycled through the PR sample several times. This was done to check for heterogeneity between PR samples and thus, enabled determination of a correction factor for differences in PR samples, based on exchange thermodynamics and not PR weight. Furthermore, this ensured the system to behave normally when the $\mathrm{K}$ and $\mathrm{Ca}$ peak areas were of equal and opposite magnitude (indicative of an exchange process).

Once the $\mathrm{K} / \mathrm{Ca}$ cycles were complete, $15 \mathrm{mM}$ $\mathrm{Pb}\left(\mathrm{NO}_{3}\right)_{2}, \mathrm{Cu}\left(\mathrm{NO}_{3}\right)_{2}$ or $\mathrm{Zn}\left(\mathrm{NO}_{3}\right)_{2}$ solutions were, respectively, reacted with the Ca-saturated PR and the heat was determined. This process was repeated three to five times for each solution composition in order to determine if the exchange reactions were reversible. The heat data were averaged and standard deviations calculated.

Each of the PR samples reacted with $\mathrm{Pb}, \mathrm{Cu}$, and $\mathrm{Zn}$ then underwent several cycles of $\mathrm{K} / \mathrm{Ca}$ solution. This was done to enable a comparison between the original (i.e. prior to metal introduction to the PR) energetics of $\mathrm{K} / \mathrm{Ca}$ exchange and post-metal energetics of $\mathrm{K} / \mathrm{Ca}$ exchange in order to ascertain changes in the energetics of cation exchange as a function of metal introduction. These solid residues were then extracted from the flow calorimeter column, washed with deionized $\mathrm{H}_{2} \mathrm{O}$ and dried in the air. The dried solid was digested in $\mathrm{HNO}_{3} / \mathrm{H}_{2} \mathrm{O}_{2}$ with USEPA Method 3050. The $\mathrm{Pb}, \mathrm{Cu}$, and $\mathrm{Zn}$ found were assumed to be chemisorbed (Appel et al., 2002).

\subsection{Analysis methods}

Metal $(\mathrm{Ca}, \mathrm{Pb}, \mathrm{Cu}, \mathrm{Zn}$, etc.) concentrations were analyzed using either a flame atomic absorption 
spectrometer (Varian 220FS) or a graphite furnace atomic absorption spectrophotometer (Perkin-Elmer model SIMMA 6000), depending on metal concentrations. Multi-level standards (Fisher Scientific) were prepared in $2 \%$ nitric acid. Elemental analysis followed a USEPA approved QA/QC plan with a blank, a duplicate, and a spike every 20 samples. Total phosphate $\left(\mathrm{PO}_{4}\right)$ concentrations were determined using visible spectroscopy via the ascorbic acid/molybdate method (Olsen and Sommers, 1982). Solution pH was determined using a Fisher Scientific Accumet model $20 \mathrm{pH} /$ conductivity meter.

Selected solid residues were examined with an X-ray diffractometer. X-ray diffraction analyses were performed on a computer-controlled X-ray diffractometer equipped with a stepping motor and graphite crystal monochromator. Scans were conducted from 2 to $60^{\circ}$ at a rate of $2^{\circ} \theta$ per minute. Selected solid residues were also observed under a scanning electron microscope (SEM, JSM-6400/TN500, JEOL, USA) equipped with $\mathrm{X}$-ray energy dispersive spectroscopy (EDS).

\section{Results and discussion}

\subsection{Sorption of $\mathrm{Pb}, \mathrm{Cu}$, and $\mathrm{Zn}$ under mono-metal and multi-metal reaction conditions}

As expected, PR was effective in retaining all three metals; however, sorption isotherms for $\mathrm{Pb}, \mathrm{Cu}$, and $\mathrm{Zn}$ at $25 \pm 2{ }^{\circ} \mathrm{C}$ and $\mathrm{pH} 5.5 \pm 0.2$ exhibited differences in shape and in the amount of metal retained (Fig. 1). Sorption behaviors of $\mathrm{Cu}$ and $\mathrm{Zn}$ were similar in both mono-metal (Fig. 1a) and multi-metal (Fig. 1b) systems, and significantly different from that of $\mathrm{Pb}$. In the case of $\mathrm{Pb}$ sorption, it was very efficient. For initial $\mathrm{Pb}$ concentrations of up to $0.4 \mathrm{mM}$, the equilibrium $\mathrm{Pb}$ concentrations were nearly at the detection limit of the analytical method employed. The obtained sorption patterns were similar to those observed elsewhere (Mavropoulos et al., 2002; Singh et al., 2001). According to Echeverria et al. (1998), isotherms that have similar equilibrium concentrations for different amounts of metal added reflect a precipitation mechanism. It appeared to be consistent with the hypothesis of Ma et al. (1995), who proposed that $\mathrm{Pb}$ retention by hydroxyapatite is controlled by hydroxyapatite dissolution, followed by hydroxypyromorphite precipitation. Similarly, $\mathrm{PR}$ induced reactions in the presence of $\mathrm{Pb}$ could be simplified as follows

$$
\begin{aligned}
& \mathrm{Ca}_{10}\left(\mathrm{PO}_{4}\right)_{6} \mathrm{~F}_{2}+12 \mathrm{H}^{+} \Leftrightarrow 10 \mathrm{Ca}^{2+}+6 \mathrm{H}_{2} \mathrm{PO}_{4}^{-}+2 \mathrm{~F}^{-} \\
& 10 \mathrm{~Pb}^{2+}+6 \mathrm{H}_{2} \mathrm{PO}_{4}^{-}+2 \mathrm{~F}^{-} \Leftrightarrow \mathrm{Pb}_{10}\left(\mathrm{PO}_{4}\right)_{6} \mathrm{~F}_{2}+12 \mathrm{H}^{+}
\end{aligned}
$$
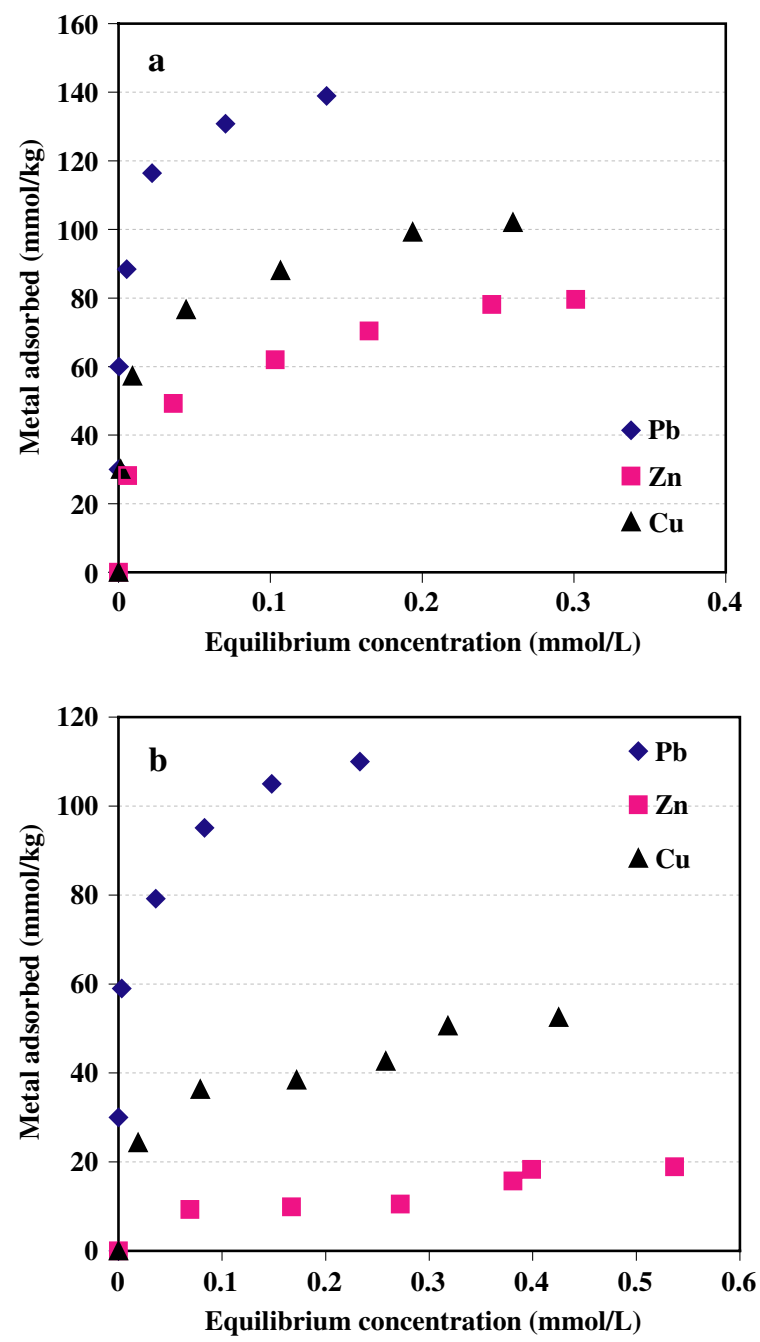

Fig. 1. Adsorption isotherms of (a) mono-metal and (b) multi-metal on phosphate rock at $\mathrm{pH} 5.5$ and $25^{\circ} \mathrm{C}$.

In the current investigation using PR, fluoropyromorphite $\left(\mathrm{Pb}_{10}\left(\mathrm{PO}_{4}\right)_{6} \mathrm{~F}_{2}\right)$ formation was confirmed by XRD and SEM element map from the residual solid after $0.4 \mathrm{mM} \mathrm{Pb}$ was equilibrated with PR (Fig. 2). The XRD patterns showed fluoropyromorphite peaks $(2.95 \AA$ and $2.98 \AA)$ after $\mathrm{Pb}$ reaction with $\mathrm{PR}$, but not in the control (Fig. 2a). SEM element map showed the association of $\mathrm{Pb}$ with $\mathrm{P}$ instead of $\mathrm{Ca}$ as expected from PR (Fig. 2b).

Copper and $\mathrm{Zn}$ retention gradually increased with increasing initial concentration and then leveled off (Fig. 1). The shape of this isotherm reflects surface adsorption or complexation mechanism (Echeverria et al., 1998). XRD analysis did not show any mineral formation in the solid of $\mathrm{Cu}$ or $\mathrm{Zn}$ reaction with phosphate (Fig. 2a), as reported in other studies (Ma et al., 1994; Xu et al., 1994). Xu et al. (1994) suggested that the dominant sorption mechanism involved $\mathrm{Zn}$ interaction with hydroxyapatite surface functional 


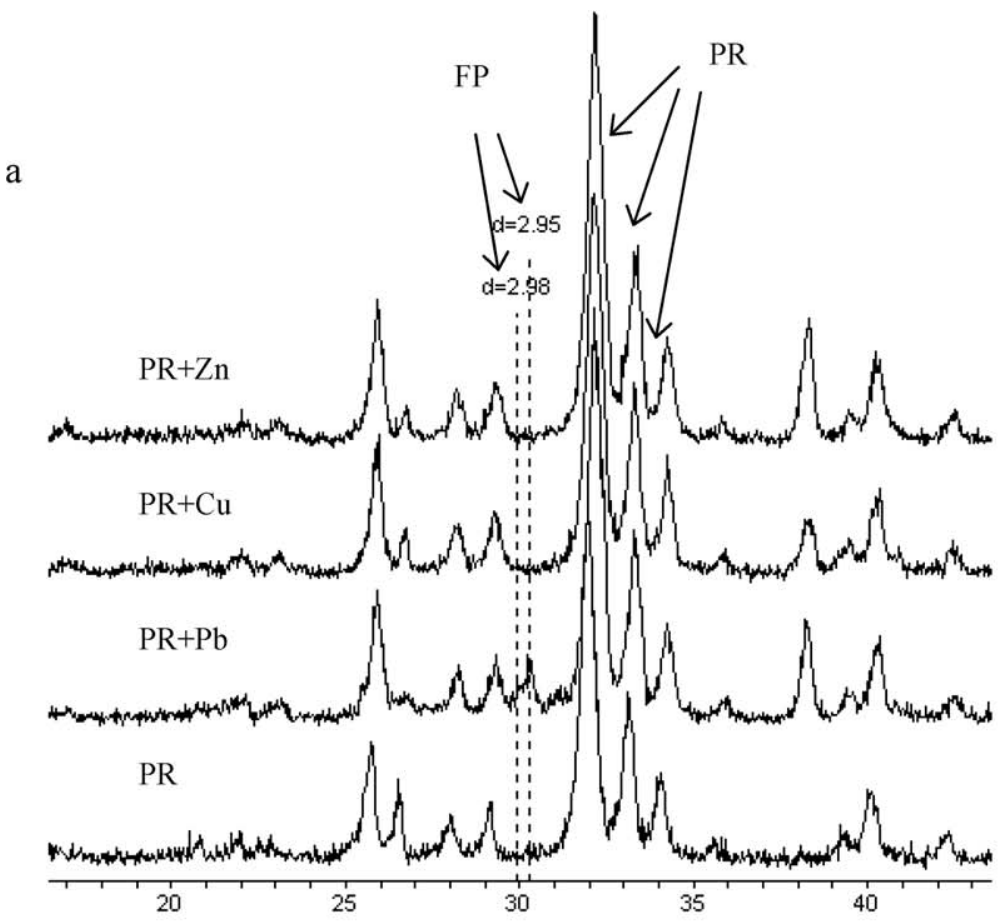

$2 \theta$

$\mathrm{b}$
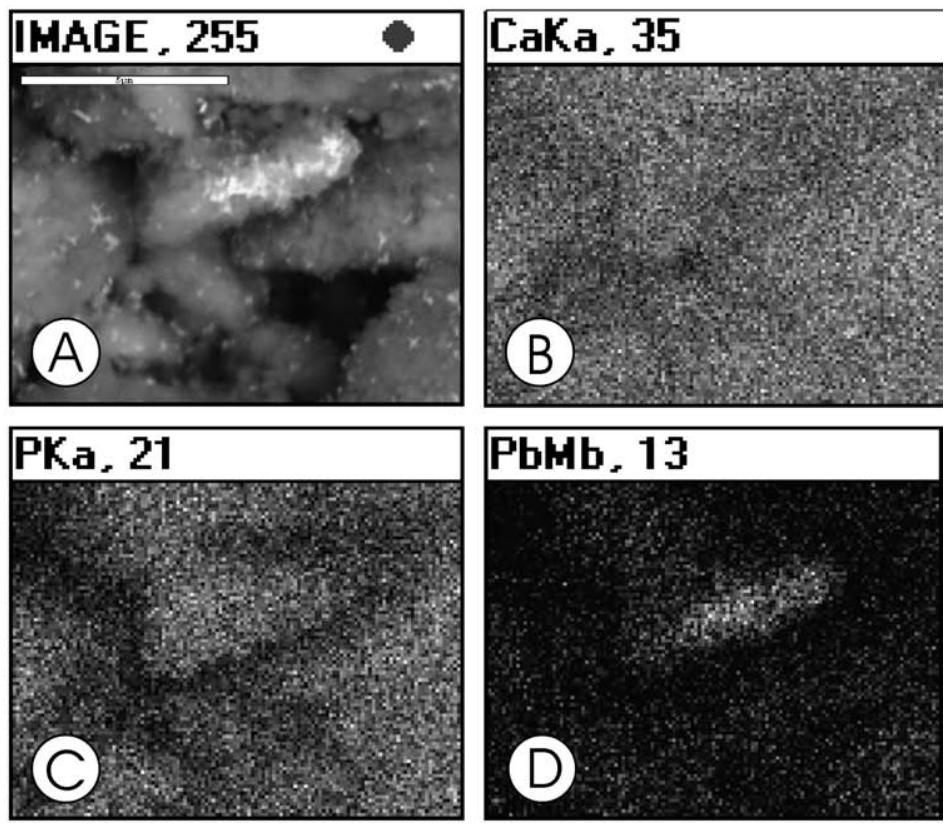

Fig. 2. X-ray diffraction patterns of (a) the residual solids from phosphate rock reaction with $0.4 \mathrm{mM} \mathrm{Pb}, \mathrm{Cu}$, and $\mathrm{Zn}$; and (b) SEM element dot map of the residual solids from phosphate rock reaction with $0.4 \mathrm{mM} \mathrm{Pb}$. FP, fluoropyromorphite; PR, phosphate rock. (A), fluoropyromorphite crystal; (B), Ca; (C), P; and (D), Pb. Scale bar $=5 \mu \mathrm{m}$.

groups such as $\equiv \mathrm{POH}$ and coprecipitation of $\mathrm{Zn}$ with $\mathrm{Ca}$ into the apatite structure.

In the $\mathrm{Pb}-\mathrm{Cu}-\mathrm{Zn}$ ternary system, competition among metals affected sorption of all metals. The initial linear part of the isotherms was shorter and the knee was sharper (Fig. 1b) when compared with mono-metal sorption (Fig. 1a). Competitive metal retention by PR suggested that complexation mechanisms may have contributed partially to metal sorption by PR. Nevertheless, fluoropyromorphite precipitation was still the main mechanism for $\mathrm{Pb}$ retention but not for $\mathrm{Cu}$ or $\mathrm{Zn}$, as demonstrated by XRD analysis (data not shown). This was apparent at $\mathrm{Pb}$ concentrations of $<0.3 \mathrm{mM}$. Reduction of fluoropyromorphite precipitation at greater $\mathrm{Pb}$ concentration 
Table 1

Langmuir parameters for the sorption of mono-metal and multi-metal onto phosphate rock

\begin{tabular}{|c|c|c|c|c|c|c|}
\hline & \multicolumn{3}{|l|}{ Mono-metal } & \multicolumn{3}{|l|}{ Multi-metal } \\
\hline & Point $B^{\mathrm{a}}(\mathrm{mmol} / \mathrm{kg})$ & $C_{\mathrm{s}}^{\mathrm{m}}(\mathrm{mmol} / \mathrm{kg})^{\mathrm{b}}$ & $B_{\mathrm{L}}^{\mathrm{c}}(\mathrm{L} / \mathrm{mmol})$ & Point $B(\mathrm{mmol} / \mathrm{kg})$ & $C_{\mathrm{s}}^{\mathrm{m}}(\mathrm{mmol} / \mathrm{kg})$ & $B_{\mathrm{L}}(\mathrm{L} / \mathrm{mmol})$ \\
\hline$\overline{\mathrm{Pb}}$ & $132 \pm 22.3^{\mathrm{d}}$ & $138 \pm 26.1$ & $351 \pm 45.7$ & $110 \pm 21.1$ & $117 \pm 23.5$ & $56.3 \pm 6.45$ \\
\hline $\mathrm{Cu}$ & $101 \pm 18.2$ & $114 \pm 12.4$ & $32.2 \pm 5.61$ & $51.2 \pm 6.78$ & $58.9 \pm 7.11$ & $20.5 \pm 3.91$ \\
\hline $\mathrm{Zn}$ & $79.6 \pm 10.3$ & $83.2 \pm 13.6$ & $12.7 \pm 3.22$ & $18.3 \pm 1.25$ & $20.3 \pm 2.33$ & $2.62 \pm 0.55$ \\
\hline
\end{tabular}

${ }^{\text {a }}$ Point $B$ is the amount of metal retained at the plateau or at the beginning of the linear portion above the isotherm's knee, which is obtained from the intersection of tangents to the origin and plateau of isotherms.

${ }^{\mathrm{b}} C_{\mathrm{s}}^{\mathrm{m}}$, Langmuir adsorption capacity.

${ }^{\mathrm{c}} B_{\mathrm{L}}$, Langmuir bounding related to interaction energies.

${ }^{\mathrm{d}}$ Mean \pm standard deviation $(n=3)$.

may result from the competition of $\mathrm{Cu}$ and $\mathrm{Zn}$ for phosphate ions (Chen et al., 1997; Mavropoulos et al., 2002).

The characteristics of heavy metal sorption onto PR could be well described by the Langmuir model

$C_{\mathrm{e}} / C_{\mathrm{s}}=C_{\mathrm{e}} / C_{\mathrm{s}}^{\mathrm{m}}+1 / C_{\mathrm{s}}^{\mathrm{m}} \cdot B_{\mathrm{L}}$

where $C_{\mathrm{s}}^{\mathrm{m}}$ denotes the Langmuir maximum capacity $(\mathrm{mmol} / \mathrm{kg}) ; C_{\mathrm{e}}$ is the concentration $(\mathrm{mmol} / \mathrm{L})$ in the equilibrium solution; $C_{\mathrm{s}}$ is the measured sorption per unit weight of PR $(\mathrm{mmol} / \mathrm{kg})$; and $B_{\mathrm{L}}$ represents the Langmuir bonding term related to interaction energies $(\mathrm{L} / \mathrm{mmol})$. Table 1 summarized Point $B, C_{\mathrm{s}}^{\mathrm{m}}$, and $B_{\mathrm{L}}$ values based on the application of the Langmuir model to mono-metal and multi-metal competitive sorption. As expected, values of Point $B, C_{\mathrm{s}}^{\mathrm{m}}$, and $B_{\mathrm{L}}$ were greater in mono-metal sorption than in the competitive sorption for all three metals. However, the amount of sorption varied with metals, following a descending order of $\mathrm{Pb}>\mathrm{Cu}>\mathrm{Zn}$ (Table 1$)$. In the ternary $\mathrm{Pb}-\mathrm{Cu}-\mathrm{Zn}$ system, competitive sorption resulted in maximum sorption reduction by $15 \%$ for $\mathrm{Pb}, 48 \%$ for $\mathrm{Cu}$, and $75 \%$ for $\mathrm{Zn}$, relative to the mono-system. The values of Point $B$, $C_{\mathrm{s}}^{\mathrm{m}}$, and $B_{\mathrm{L}}$ for $\mathrm{Pb}$ clearly indicated that $\mathrm{PR}$ has the highest affinity for $\mathrm{Pb}$.

During metal retention by PR, solution Ca increased with increasing metal disappearance (Fig. 3a). The greatest increase was found with $\mathrm{Pb}$ sorption. Unlike $\mathrm{Ca}, \mathrm{P}$ decreased with increasing metal reduction. The largest $\mathrm{P}$ reduction was also found with $\mathrm{Pb}$ sorption (Fig. 3b). The fact that $\mathrm{Pb}$ sorption by $\mathrm{PR}$ induced the greatest increase in solution Ca concentration as well as the largest decrease in $\mathrm{P}$ concentration is consistent with the hypothesis that $\mathrm{Pb}$ retention by $\mathrm{PR}$ was through the dissolution of PR (release $\mathrm{Ca}$ and $\mathrm{P}$ into solution) and formation of fluoropyromorphite (consumption of $\mathrm{P}$ ). Though, to a lesser extent, $\mathrm{Ca}$ levels increased and $\mathrm{P}$ levels decreased upon reaction of $\mathrm{Cu}$ and $\mathrm{Zn}$ with $\mathrm{PR}$. Thus, we cannot exclude the possibility of $\mathrm{Cu}-$ and $\mathrm{Zn}$-phosphate precipitation or coprecipitation of $\mathrm{Cu}$ and $\mathrm{Zn}$ with PR. In the studies of hydroxyapatite with aqueous $\mathrm{Zn}$, Ma et al. (1994) speculated precipitation of amorphous to poorly crystalline $\mathrm{Zn}$ phosphate. $\mathrm{Xu}$ et al. (1994) suggested possible coprecipitation of $\mathrm{Zn}$ with $\mathrm{Ca}$ to form solid when aqueous $\mathrm{Zn}$ reacted with apatite. However, according to LeGeroes and LeGeroes (1984), cations with ionic radii smaller than $\mathrm{Ca}^{2+}(0.099 \mathrm{~nm})$ have a lower probability of being incorporated into an apatite structure compared with larger ionic radii of $\mathrm{Pb}$
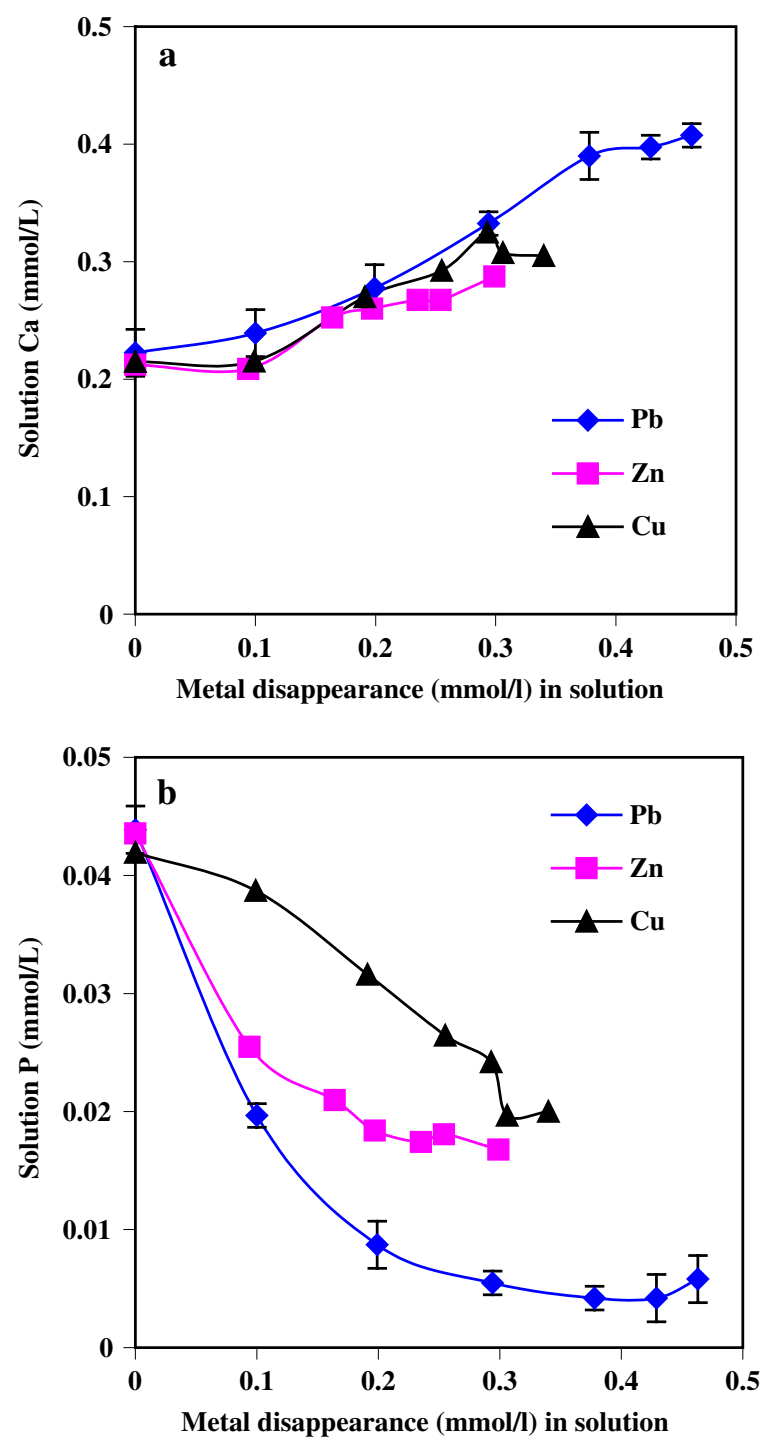

Fig. 3. Calcium (a) and $\mathrm{P}$ (b) in equilibrium solution as a function of metal disappearance. 
$(0.118 \mathrm{~nm})$. Therefore, coprecipitation of $\mathrm{Zn}(0.088 \mathrm{~nm})$ and $\mathrm{Cu}(0.087 \mathrm{~nm})$ with $\mathrm{Ca}$ in the presence of PR would be less likely to occur compared to $\mathrm{Pb}$.

Calcium was the main cation in PR, constituting $34.3 \%$ on a mass basis (Singh et al., 2001). Calcium release appeared to be related to the amount of $\mathrm{Pb}, \mathrm{Cu}$, and $\mathrm{Zn}$ sorbed (Fig. 3a). The amount of Ca released in monometal isotherms upon addition of $\mathrm{Pb}, \mathrm{Cu}$, and $\mathrm{Zn}$ showed a linear function with the amount of each metal sorbed (Fig. 4a). A linear relationship with a slope $=0.92$ $\left(r^{2}=0.96\right)$ was obtained when Ca released was plotted as a function of $\mathrm{Pb}$ sorbed. The nearly $1: 1$ ratio of $\mathrm{Ca}_{\text {released }} / \mathrm{Pb}_{\text {sorbed }}$ may indicate equal displacement of $\mathrm{Ca}$ by $\mathrm{Pb}$ during dissolution of $\mathrm{PR}$ and formation of fluoropyromorphite (Singh et al., 2001). Substitution of $\mathrm{Pb}$ for $\mathrm{Ca}$ during fluoropyromorphite formation may also have contributed to $\mathrm{Pb}$ retention. Slopes for $\mathrm{Cu}$ and $\mathrm{Zn}$ were $0.65\left(r^{2}=0.92\right)$ and $0.41\left(r^{2}=0.93\right)$, respectively, indicating other retention mechanisms
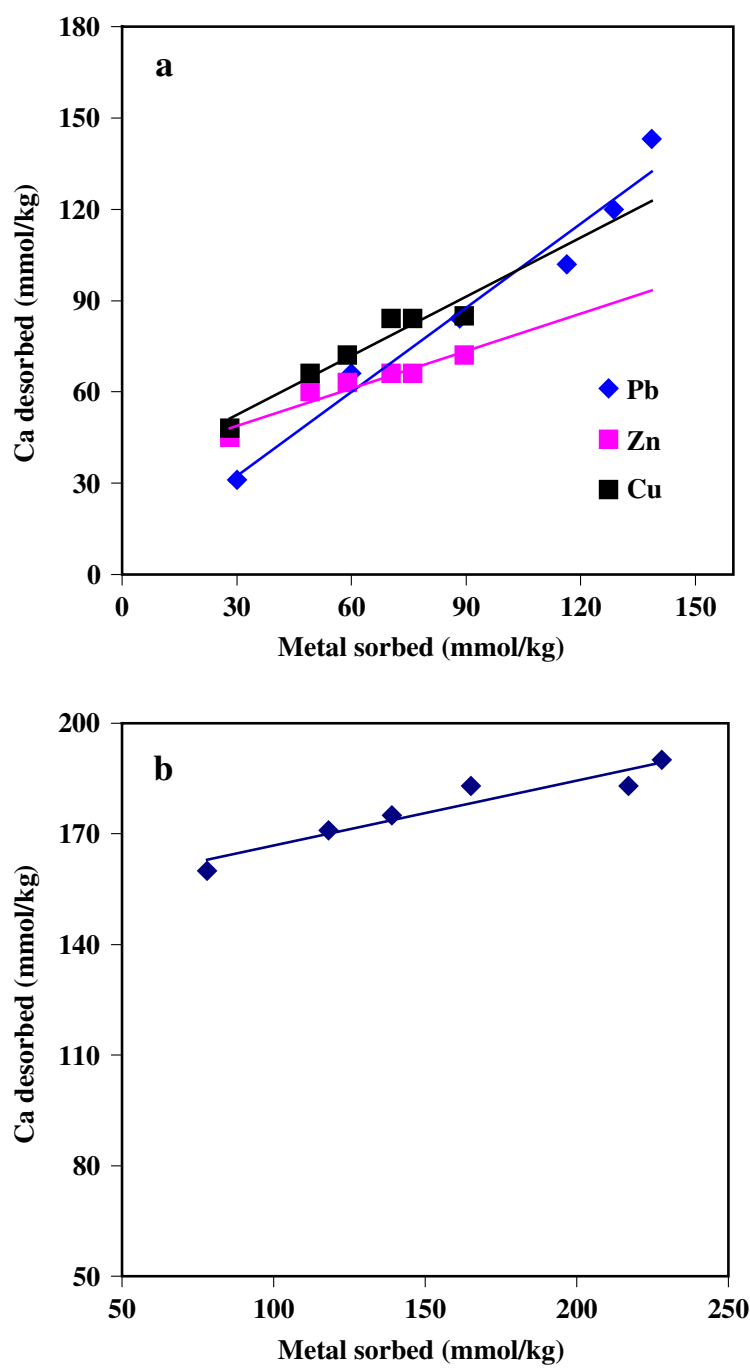

Fig. 4. Correlation between metal sorbed and Ca released at (a) monometal system and (b) multi-metal system. than cationic exchange, probably surface complexation. For the multi-metal sorption, although a positive linear correlation was still observed between the amount of $\mathrm{Ca}$ released and the amount of total metal sorbed (Fig. 4b), the molar ratios of $\mathrm{Ca}_{\text {released }} / \mathrm{M}_{\text {sorbed }}$ were reduced to 0.17 $\left(r^{2}=0.96\right)$ due to the competitive complexation (Chen et al., 1997).

In order to know what happened about the proton change during the metal uptake, the reaction system was free of acidity control and the final $\mathrm{pH}$ was monitored at different initial metal concentrations. Obviously, metal uptake caused a significant decrease of solution $\mathrm{pH}$ by up to 1.5 unit change (Fig. 5). Similar results were observed in previous studies (Mavropoulos et al., 2002; Singh et al., 2001; Xu et al., 1994). In this study, metal retention induced $\mathrm{pH}$ reduction from 6.83 to 5.38-5.56, which was less than the PZC of PR, i.e. 6.87. In a $\mathrm{pH}$ range of $<6.87, \equiv \mathrm{POH}$ is a dominant functional group for PR (Wu et al., 1991). Visual MINTEQ modeling (Gustafsson, 2001) indicated that $>85 \% \mathrm{Cu}$ and $\mathrm{Zn}$ were present in $\mathrm{Cu}^{2+}$ and $\mathrm{Zn}^{2+}$. Thus, when $\mathrm{Cu}$ and $\mathrm{Zn}$ were mixed with phosphate rock, complexation occurred on the PR surface, partially displacing the $\mathrm{H}^{+}$ ions and resulting in $\mathrm{pH}$ decline as described in Eqs. (4) and (5):

$$
\begin{aligned}
& \equiv \mathrm{POH}+\mathrm{Cu}^{2+}=\equiv \mathrm{POCu}^{+}+\mathrm{H}^{+} \\
& \equiv \mathrm{POH}+\mathrm{Zn}^{2+}=\equiv \mathrm{POZn}^{+}+\mathrm{H}^{+} \\
& \equiv \mathrm{POH}+\mathrm{Pb}^{2+}=\equiv \mathrm{POPb}^{+}+\mathrm{H}^{+}
\end{aligned}
$$

In the case of $\mathrm{Pb}$, although $\mathrm{PR}$ dissolution consumed $\mathrm{H}^{+}$(Eq. (1)), fluoropyromorphite precipitation liberated an equal amount of $\mathrm{H}^{+}$(Eq. (2)). In other words, in theory uptake of $\mathrm{Pb}$ via fluoropyromorphite precipitation should not cause a net $\mathrm{pH}$ change (Mavropoulos

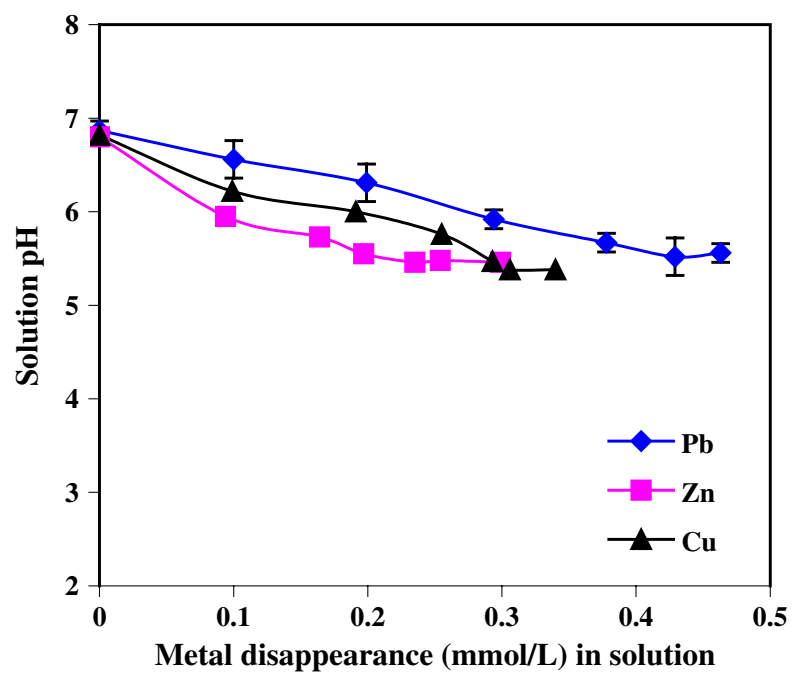

Fig. 5. Final solution $\mathrm{pH}$ as a function of solution metal disappearance. 
et al., 2002). If this is the case, then other surface mechanisms besides PR dissolution and fluoropyromorphite precipitation may have contributed to $\mathrm{pH}$ decrease. One possibility was $\mathrm{Pb}$ complexation at the $\mathrm{PR}$ surface as shown in Eq. (6). So the solution $\mathrm{pH}$ decrease could be linked to the proton liberated by $\mathrm{Pb}$ complexation at $\equiv \mathrm{POH}$ sites.

Visual MINTEQ modeling (Gustafsson, 2001) indicated that the solutions were undersaturated with respect to $\mathrm{Pb}(\mathrm{OH})_{2}$ or $\mathrm{Cu}(\mathrm{OH})_{2}$. Thus, the reduction in solution $\mathrm{pH}$ cannot be contributed to hydrolysis of $\mathrm{Pb}^{2+}$ or $\mathrm{Cu}^{2+}$. Clearly, more metal disappearance (adsorbed by PR) would release more $\mathrm{H}^{+}$, resulting in a greater $\mathrm{pH}$ reduction (Fig. 5).

\subsection{Competition-induced inhibition}

The effects of the other two metals on the retention of the third metal, determined by the fractional factorial design, are shown in Fig. 6. Because metals were not added in the same initial concentrations (Table 2), and to avoid possible distortions, results are expressed as percentage of the retained metals with respect to Point $B$ of mono-metal isotherms. In the ternary system, $\mathrm{Pb}, \mathrm{Cu}$, and $\mathrm{Zn}$ sorption reflected a remarkably competitive effect as shown in Fig. 1. The presence of other metals significantly reduced the sorption of the third metal. The percentage of metals sorbed onto the PR was in the order of $\mathrm{Pb}(60-68 \%)>\mathrm{Cu}(42-56 \%) \gg \mathrm{Zn}(<10 \%)$, compared to the mono-metal sorption. Therefore, $\mathrm{Pb}$ is the metal that experienced the least reduction in the competitive sorption process, consistent with the results of Ma et al. (1994), i.e. $\mathrm{Cu}$ and $\mathrm{Zn}$ had little influence on the $\mathrm{Pb}$ immobilization in the presence of phosphate. Conversely, $\mathrm{Pb}$ significantly inhibited the retention of $\mathrm{Cu}$ and $\mathrm{Zn}$ (Ma et al., 1994). According to Fig. 6, Zn had less influence than $\mathrm{Cu}$ on $\mathrm{Pb}$ retention, whereas $\mathrm{Zn}$ was most affected in the competitive sorption. The results showed that $\mathrm{PR}$ was most effective in $\mathrm{Pb}$ immobilization even in the ternary competitive system.

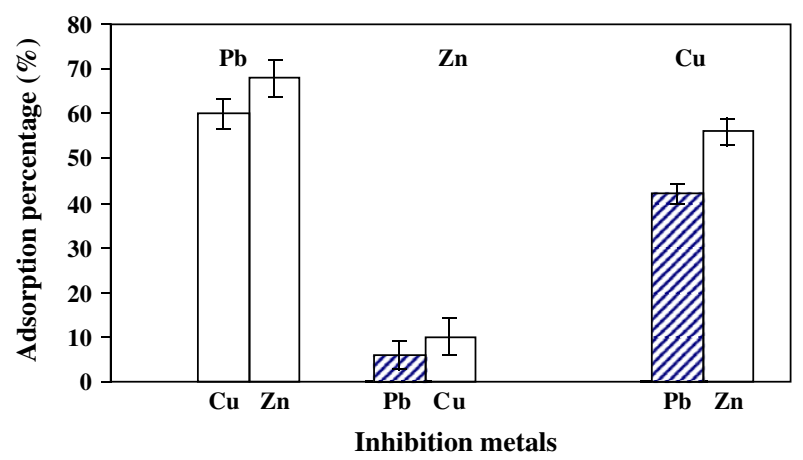

Fig. 6. Percentage of sorption of $\mathrm{Pb}, \mathrm{Cu}$, and $\mathrm{Zn}$ by phosphate rock in the fractional factorial experiment (in relation to the Point $B$ of individual metals).
Table 2

Initial concentrations of $\mathrm{Pb}, \mathrm{Cu}$, and $\mathrm{Zn}(\mathrm{mmol} / \mathrm{L})$ in the fractional factorial experiments

\begin{tabular}{llll}
\hline Run & Factors & & \\
\cline { 2 - 4 } & $\mathrm{Pb}$ & $\mathrm{Cu}$ & $\mathrm{Zn}$ \\
\hline 1 & 0.51 & 0.44 & 0 \\
2 & 0 & 0.44 & 0.49 \\
3 & 0.51 & 0 & 0.49 \\
4 & 0 & 0 & 0 \\
\hline
\end{tabular}

\subsection{Desorption of sorbed metals}

Heavy metal desorption from PR depended on the $\mathrm{pH}$ of the extracting solutions (Fig. 7). Copper and $\mathrm{Zn}$ desorption significantly increased with $\mathrm{pH}$ decrease. In the $\mathrm{pH}$ range of 3-9, $\mathrm{Cu}$ and $\mathrm{Zn}$ were desorbed by up to $35 \%$ and $55 \%$ of total adsorbed, respectively (Fig. 7). As described above, a substantial fraction of sorbed $\mathrm{Cu}$ and $\mathrm{Zn}$ was weakly bound by complexation, thus, $\mathrm{pH}$ reduction induced greater $\mathrm{Cu}$ and $\mathrm{Zn}$ solubility. However, $\mathrm{Pb}$ desorption was different from those of $\mathrm{Cu}$ and $\mathrm{Zn}$. First, much less $\mathrm{Pb}$ was desorbed, i.e. $<12 \%$ in the $\mathrm{pH}$ range of 3-9 (Fig. 7). Also, the $\mathrm{Pb}$ desorption decreased as $\mathrm{pH}$ decreased from 4.93 to 2.93, though $\mathrm{Pb}$ desorption increased as $\mathrm{pH}$ decreased from 9.0 to 4.93, like $\mathrm{Cu}$ and $\mathrm{Zn}$. Inconsistent $\mathrm{Pb}$ desorption responding to solution $\mathrm{pH}$ may indicate that not all the $\mathrm{Pb}$ was chemisorbed by precipitating as fluoropyromorphite, and a fraction of $\mathrm{Pb}$ was weakly adsorbed or complexed on the surface of PR. Comparing the total amount of the immobilized $\mathrm{Pb}$ with the $\mathrm{Pb}$ incorporated into the hydroxypyromorphite phase, Mavropoulos et al. (2002) concluded that up to $30 \%$ of $\mathrm{Pb}$ was immobilized by other surface mechanisms such as adsorption or complexation besides apatite dissolution and

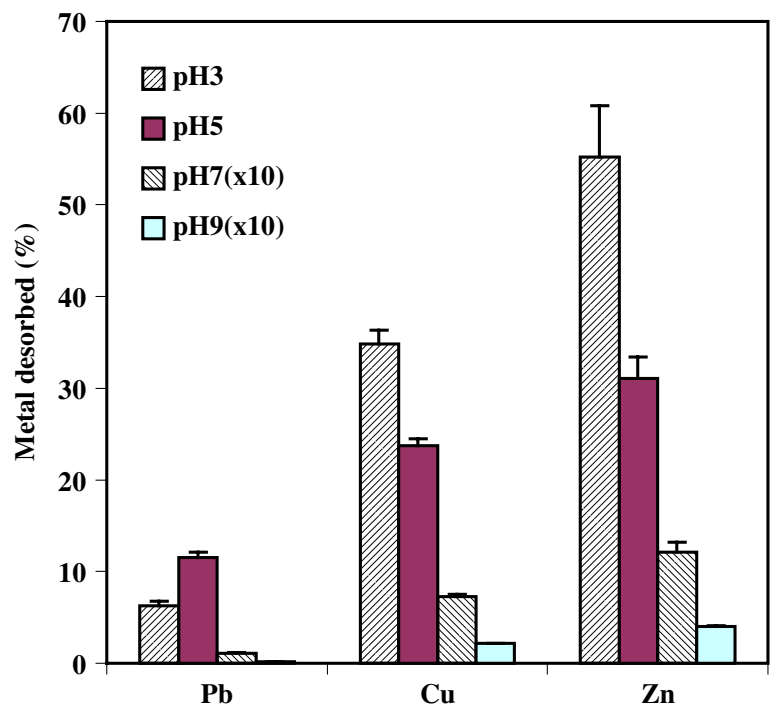

Fig. 7. Effects of $\mathrm{pH}$ on $\mathrm{Pb}, \mathrm{Cu}$, and $\mathrm{Zn}$ desorption after $0.4 \mathrm{mM}$ metal reaction with phosphate rock. 
hydroxypyromorphite crystallization. So the high acidity of $\mathrm{pH}=2.93$ is likely to induce dissolution of both weakly-bound $\mathrm{Pb}$ and $\mathrm{PR}$, facilitating formation of fluoropyromorphite and leading to reduction of $\mathrm{Pb}$ desorption (Basta et al., 2001). It should be pointed out that TCLP solution of $\mathrm{pH} 2.93$ contains a high acetate concentration $(0.15 \mathrm{M})$, thus, acetate may complex with $\mathrm{Pb}$ to form $\mathrm{Pb}\left(\mathrm{CH}_{3} \mathrm{COO}\right)_{2}$, increasing $\mathrm{Pb}$ solubility. However, $\mathrm{Pb}\left(\mathrm{CH}_{3} \mathrm{COO}\right)_{2}$ would be ultimately transformed into insoluble fluoropyromorphite. Comparing desorption of the three metals, it appears that $\mathrm{Zn}$ and $\mathrm{Cu}$ sorption to $\mathrm{PR}$ is sensitive to $\mathrm{pH}$, whereas $\mathrm{Pb}$ phosphate precipitation stayed intact under a wide range of $\mathrm{pH}$ from 3 to 9. It suggested a greater stability of $\mathrm{Pb}$ immobilization, compared to $\mathrm{Cu}$ and $\mathrm{Zn}$. This again demonstrates that PR could be used effectively to remove $\mathrm{Pb}$ from wastewater or remediate $\mathrm{Pb}$-contaminated soil and sediments through formation of fluoropyromorphite even at low $\mathrm{pH}$ and in the presence of other contaminants.

\subsection{Flow calorimetric analysis of $\mathrm{Pb}, \mathrm{Cu}$, and $\mathrm{Zn}$ sorption}

Flow calorimetry enables the direct measurement of the heat associated with a reaction (Rhue et al., 2002; Steinberg, 1981). This is related to the enthalpy change $(\Delta H)$, which, in the case of surface reactions, provides information about the binding strength of a particular ionic species to the solid (Appel et al., 2002). In the present study, the sorption of $\mathrm{Pb}$ and $\mathrm{Cu}$ by $\mathrm{PR}$ was exothermic with heats of 19.1 and $14.3 \mathrm{~kJ} / \mathrm{mol}$, respectively, whereas sorption of $\mathrm{Zn}$ was endothermic, $7.25 \mathrm{~kJ} / \mathrm{mol}$ (Table 3 ).

Heats for $\mathrm{K} / \mathrm{Ca}$ exchange before and after $\mathrm{Cu}$ and $\mathrm{Zn}$ sorption were not significantly different (data no shown), which is consistent with the weaker binding of these metals to the PR surface. This was evidenced by the small amount of non-exchangeable $\mathrm{Cu}$ and $\mathrm{Zn}$ (retarded in the column after $\mathrm{K} / \mathrm{Ca}$ exchange following $\mathrm{Pb}$ sorption), i.e. 25.5 and $4.33 \%$ of the maximum sorbed, respectively (Tables 1 and 3). By comparison, the heat for $\mathrm{K} / \mathrm{Ca}$ exchange following $\mathrm{Pb}$ sorption was less than half of what it was before $\mathrm{Pb}$ sorption,

Table 3

Heats of sorption, solution $\mathrm{pH}$, and non-exchangeable metal measured based on flow calorimetric analysis

\begin{tabular}{llcll}
\hline Metals & $\begin{array}{l}\text { Heats } \\
(\Delta H, \mathrm{~kJ} / \mathrm{mol})\end{array}$ & $\begin{array}{l}\text { Input } \mathrm{pH} / \\
\text { output } \mathrm{pH}\end{array}$ & $\begin{array}{l}\text { Non-exchangeable } \\
\text { metal } \\
\left(\mathrm{mmol} / \mathrm{kg} \mathrm{PR}^{\mathrm{a}}\right)\end{array}$ & $\begin{array}{l}\% \text { of total } \\
\text { metal } \\
\text { retained }\end{array}$ \\
\hline $\mathrm{Pb}$ & $-19.1 \pm 3.52^{\mathrm{b}}$ & $5.18 / 5.11$ & $108 \pm 12.1$ & 78.3 \\
$\mathrm{Cu}$ & $-14.3 \pm 2.76$ & $5.33 / 5.36$ & $29.1 \pm 2.17$ & 25.5 \\
$\mathrm{Zn}$ & $7.25 \pm 0.92$ & $5.41 / 5.44$ & $3.60 \pm 0.43$ & 4.33 \\
\hline
\end{tabular}

\footnotetext{
${ }^{\text {a }}$ Phosphate rock.

${ }^{\mathrm{b}}$ Mean \pm standard deviation $(n=3)$.
}

consistent with an irreversible sorption of $\mathrm{Pb}$ to the PR surface. Phosphate rock irreversibly sorbed $108 \mathrm{mmol} \mathrm{Pb} / \mathrm{kg}$ of PR (non-exchangeable) (Table 3), accounting for $78.3 \%$ of the maximum sorption capacity (Table 1). The sorption of $\mathrm{Pb}$ was mainly attributed to the precipitation via fluoropyromorphite. XRD analysis of the solid samples taken from the calorimeter following $\mathrm{Pb}$ treatment indicated the presence of fluoropyromorphite (data not shown). The reversibly sorbed $\mathrm{Pb}, 21.7 \%$, could have been held by surface sorption/ complexation reactions, more like those binding $\mathrm{Cu}$ and $\mathrm{Zn}$ to the PR surface.

\section{Conclusions}

Phosphate rock has the highest affinity for $\mathrm{Pb}$, followed by $\mathrm{Cu}$, and then $\mathrm{Zn}$. The sorption of $\mathrm{Pb}, \mathrm{Cu}$, and $\mathrm{Zn}$ onto PR was well characterized by the Langmuir model. Multi-metal addition induced competitive sorption among the three metals, with the interfering effect of $\mathrm{Pb}>\mathrm{Cu}>\mathrm{Zn}$.

Lead immobilization was primarily attributed to phosphate-induced fluoropyromorphite formation, and to a lesser extent, to the surface adsorption or complexation. $\mathrm{Up}$ to $78.3 \%$ of sorbed $\mathrm{Pb}$ was irreversibly chemisorbed onto the PR via formation of fluoropyromorphite precipitation. In comparison, $\mathrm{Cu}$ and $\mathrm{Zn}$ were less chemisorbed (i.e. 25.5 and $4.33 \%$ ) with the rest via surface adsorption or complexation. Reduction in solution $\mathrm{pH}$ during metal retention supports the hypothesis of $\mathrm{Pb}, \mathrm{Cu}$, and $\mathrm{Zn}$ surface adsorption or complexation. Sorption of $\mathrm{Pb}$ and $\mathrm{Cu}$ by $\mathrm{PR}$ was exothermic and that for $\mathrm{Zn}$ was endothermic.

\section{Acknowledgements}

This research was supported in part by the Florida Institute of Phosphate Research (Contract No. 01-01172). The authors would like to thank Dr. Willie G. Harris for his assistance in mineral analysis and $\mathrm{Mr}$. Thomas Luongo for his assistance in chemical analysis and in pre-reading the manuscript.

\section{References}

Ahmed, S., Chughtai, S., Keane, M.A., 1998. The removal of cadmium and lead from aqueous solution by ion exchange with $\mathrm{Na}-\mathrm{Y}$ zeolite. Sep. Purif. Technol. 13, 57-64.

Appel, C., Rhue, D., Ma, L., Reve, B., 2002. Enthalpies of K/Ca and $\mathrm{K} / \mathrm{Pb}$ exchange in two tropical soils as measured by flow calorimetry. Soil Sci. 167, 773-781.

Basta, N.T., Gradwohl, R., Snethen, K.L., Schroder, J.L., 2001. Chemical immobilization of lead, zinc, and cadmium in smeltercontaminated soils using biosolids and rock phosphate. J. Environ. Qual. 30, 1222-1230. 
Cao, X., Ma, L.Q., Chen, M., Singh, S.P., Harris, W.G., 2002. Impacts of phosphate amendments on lead biogeochemistry at a contaminated site. Environ. Sci. Technol. 36, 5296-5304.

Chen, X., Wright, J.V., Concha, J.L., Peurrung, L.M., 1997. Effects of $\mathrm{pH}$ on heavy metal sorption on mineral apatite. Environ. Sci. Technol. 31, 624-631.

Cotter-Howells, J., Caporn, S., 1996. Remediation of contaminated land by formation of heavy metal phosphates. Appl. Geochem. 11, $335-342$

Echeverria, J.C., Morera, M.T., Mazkiaran, C., Garrido, J.J., 1998. Competitive sorption of heavy metal by soils. Isotherms and fractional factorial experiments. Environ. Pollut. 101, 275-284.

Elrashidi, M.A., O'Connor, G.A., 1982. Influence of solution composition on sorption of zinc by soils. Soil Sci. Soc. Am. J. 46, 1153-1158.

Gomes, P.C., Fontes, M., Silva, A.G.D., Mendonca, E.D.S., Netto, A.R., 2001. Selectivity sequence and competitive adsorption of heavy metals by Brazilian soils. Soil Sci. Soc. Am. J. 65, $1115-1121$.

Gregg, S.J., Sing, K.S.W., 1982. Adsorption, surface area and porosity, second ed. Academic Press, London.

Gustafsson, J.P., 2001. Available from: http://amov.ce.kth.se/ PEOPLE/gustafjp/vminteq2.htm.

Harter, R.D., 1992. Competitive sorption of cobalt, copper, and nickel ions by a calcium saturated soil. Soil Sci. Soc. Am. J. 56, 444-449.

Hettiarachchi, G.M., Pierzynski, G.M., Ransom, M.D., 2000. In situ stabilization of soil lead using phosphorous and manganese oxide. Environ. Sci. Technol. 34, 4614-4619.

Jeanjean, J., Vincent, U., Fedoroff, M., 1994. Structural modification of calcium hydroxyapatite induced by sorption of cadmium ions. J. Solid State Chem. 108, 68-72.

LeGeroes, R.Z., LeGeroes, J.P., 1984. Phosphate minerals in human tissues. In: Nariagu, J.O. (Ed.), Phosphate Minerals. SpringerVerlag, Berlin, pp. 351-385.

Ma, L.Q., Logan, T.J., Traina, S.J., 1995. Lead immobilization from aqueous solutions and contaminated soils using phosphate rocks. Environ. Sci. Technol. 29, 1118-1126.
Ma, Q.Y., Traina, S.J., Logan, T.J., Ryan, J.A., 1994. Effects of aqueous $\mathrm{Al}, \mathrm{Cd}, \mathrm{Cu}, \mathrm{Fe}(\mathrm{II}), \mathrm{Ni}$, and $\mathrm{Zn}$ on $\mathrm{Pb}$ immobilization by hydroxyapatite. Environ. Sci. Technol. 28, 1219-1228.

Mavropoulos, E., Rossi, A.M., Costa, A.M., Perez, C.A.C., Moreira, J.C., Saldanha, M., 2002. Studies on the mechanisms of lead immobilization by hydroxyapatite. Environ. Sci. Technol. 36, $1625-1629$

Middelburg, J.J., Comans, R.N.J., 1991. Sorption of cadmium on hydroxyapatite. Chem. Geol. 90, 45-53.

Olsen, S.R., Sommers, L.E., 1982. Phosphorus. In: Page, A.L., et al. (Eds.), Methods of Soil Analysis Part 2: Chemical and Microbiological Properties, vol. 9 second ed., ASA. Madison, Wisconsin, pp. 407-414.

Rhue, R.D., Appel, C., Kabengi, N.J., 2002. Measuring surface chemical properties of soil using flow calorimetry. Soil Sci. 167, 782-790.

Ryan, J.A., Zhang, P., Hesterberg, D., Chou, J., Sayers, D.E., 2001. Formation of chloropyromorphite in a lead-contaminated soil amended with hydroxyapatite. Environ. Sci. Technol. 35, 3798-3803.

Singh, S.P., Ma, L.Q., Harris, W.G., 2001. Heavy metal interactions with phosphatic clay: sorption and desorption. J. Environ. Qual. 30, 1961-1968.

Steinberg, G., 1981. What you can do with surface calorimetry. CHEMTECH December, 730-737.

Takeuchi, Y., Arai, H., 1990. Removal of coexisting $\mathrm{Pb}^{2+}, \mathrm{Cu}^{2+}$, and $\mathrm{Cd}^{2+}$ ions from water by addition of hydroxyapatite powder. J. Chem. Eng. Jpn. 23, 75-80.

USEPA, 1992. Toxicity characteristic leaching procedure (method 1311) in SW-846. Office of Solid Waste, Washington, DC.

Wu, L., Forsling, W., Schindler, P.W., 1991. J. Colloid Interface Sci. $147,178-185$.

$\mathrm{Xu}$, Y., Schwartz, F.W., Traina, S.J., 1994. Sorption of $\mathrm{Zn}^{2+}$ and $\mathrm{Cd}^{2+}$ on hydroxyapatite surfaces. Environ. Sci. Technol. 28 , $1472-1480$.

Yang, J., Mosby, D.E., Casteel, S.W., Blancher, R.W., 2001. Lead immobilization using phosphoric acid in a smelter-contaminated urban soil. Environ. Sci. Technol. 3553-3559. 